\title{
Determination of Rare Earth Elements, Yttrium, Thorium, and Other Trace Elements in Monazite Samples by Inductively Coupled Plasma Mass Spectrometry
}

\author{
V. Padmasubashini ${ }^{\mathrm{a} *}$ and K. Satyanarayana ${ }^{\mathrm{b}}$ \\ ${ }^{a}$ Chemistry Group, Atomic Minerals Directorate for Exploration and Research, \\ Begumpet, Hyderabad-500016, India \\ b Rajiv Gandhi University of Knowledge Technologies, I.I.I.T- Basara, \\ Adilabad District, A.P-504107, India
}

\begin{abstract}
Analysis of monazite, an important mineral of rare earth elements (REEs), and thorium constitutes one of the toughest tasks in analytical chemistry as it is a highly resistant mineral and extremely difficult to completely decompose. In the present work, inductively coupled plasma mass spectrometry (ICPMS) was applied to the determination of all individual REEs as well as other constituents like thorium, uranium, and zirconium in monazite samples originating from different places on the coast of India. Two different sample decomposition methods were used: one employing sulphuric acid decomposition and another using a fusion with a mixture of $\mathrm{KHF}_{2}$ and $\mathrm{NaF}$ in a 3:1 ratio. A mathematical correction scheme based on oxide yield and abundance data was applied to correct for the mass spectral interferences of LREE oxide ions on HREE ions.
\end{abstract}

The analytical results obtained by both methods were found to compare well with each other as well as with the results obtained by ICP-OES in the case of REEs, uranium, and thorium. However, in the case of zirconium, quantitative recoveries were obtained only with the fluoride fusion method. Though international monazite reference materials are available, certified or even probable values are not available for all the constituent elements. A certified monazite reference material, BGS: IGS-36 (British Geological Survey/Institute of Geological Sciences, U.K) was analyzed, and the results obtained are presented in this paper. The analytical results by both methods were found to compare well with each other and with the accepted values reported in literature for IGS-36. The $\%$ RSD for all the estimated elements varied from 1.0 to $4.0 \%$ at $\mathrm{mg} \mathrm{g}^{-1}$ levels and from 5.0 to $15.0 \%$ at $\mu \mathrm{g} \mathrm{g}^{-1}$ levels of concentration.

\section{INTRODUCTION}

The rare earth elements (REEs) have emerged as an important group of elements which contribute greatly to research in the geosciences as well as in several important applications based on highly advanced technologies. The

\footnotetext{
*Corresponding autbor. E-mail: padmasubasbini@gmail.com; padmasubashini.amd@gov.in
}

knowledge of their distribution in a wide range of rock types is necessary for many geochemical and petrogenetic investigations (1). In industry, REEs have found a place in the manufacture of many high quality alloys used in several hitech/strategic applications (2). In view of the above, there is a constant need for the development of new analytical methodologies for the determination of REEs in different types of geological materials as well as for improving existing methodologies.

The most important minerals of rare earth elements are monazite and xenotime which occur in small amounts (generally less than $2 \%$ ) in heavy mineral concentrates obtained from placer deposits. Monazite is a radioactive phosphate mineral with very high and variable concentrations of REEs and thorium (45-57\% REE oxides; 3-9\% $\mathrm{ThO}_{2}$; a few wt $\% \mathrm{Y}_{2} \mathrm{O}_{3}$ ). Among several components that appear in monazites, traces of lead and uranium in combination with minor thorium concentrations are used for determining the age of a rock by the $\mathrm{U}-\mathrm{Th}-\mathrm{Pb}$ method commonly used in geochronology (3).

The analysis of monazite presents a serious challenge to the analyst. Isotope dilution mass spectrometry (IDMS), neutron activation analysis (NAA), and inductively coupled plasma optical emission and mass spectrometry (ICP-OES and ICP-MS) have been employed successfully for monazite analysis. Though NAA and IDMS are two principal techniques for REE determination in geological samples, especially at very low levels, both are time-consuming, involving lengthy and laborious experimental procedures. Parthasarathy and coworkers (4) used radio-chemical neutron activation analysis for the first time for the determination of all REEs (except thulium) in Indian monazites. They determined the heavy REEs (HREEs) from holmium onwards (i.e., Tb, Dy, Ho, Er, Tm, 
$\mathrm{Yb}$, and $\mathrm{Lu}$ ) in irradiated samples after separation of the light REEs (LREEs) (i.e., La, Ce, Pr, Nd, and Sm). IDMS, though it provides highly precise results, cannot be applied to the determination of $\mathrm{Pr}$, $\mathrm{Ho}, \mathrm{Tb}$, and $\mathrm{Tm}$ because they are mono isotopic (5).

In recent years, ICP-OES has emerged as a widely used technique for trace element determinations, especially for REEs, and has been applied to their determination in different types of geological materials like rocks, ores, minerals, and concentrates (6-8). However, ICPOES methods often suffer from spectral and physical interferences, especially in the case of complicated sample matrices like monazite. It is not possible to determine the trace constituents of interest in such matrices by ICP-OES without carrying out chemical separation of the analytes from the matrix before aspiration into the plasma since thorium, present at high concentrations, emits a highly line-rich spectrum which causes severe spectral interferences in the determination of several other trace constituents In such cases, ion-exchange (9) or high-performance liquid chromatography (10) have been applied for the separation of REEs from interfering matrices. In order to achieve quantitative recoveries and to avoid loss of analytes, a single-step separation technique was adopted by some workers (11-13) for the determination of REEs. A comparative evaluation of REE distribution in the monazite and xenotime minerals by ion chromatography and ICPOES was carried out by Borai and others (14). Apart from the interference by the heavy thorium matrix, very high concentrations (20-30\%) of some of the LREEs make accurate ICP-OES determination of some of the HREEs at very low concentrations difficult, especially in monazites where the LREE to HREE ratios are very high. Hence, effective separation of LREEs is neces- sary to achieve accurate analysis of HREEs in monazite. Premdas and Khorge (15) reported solvent-based methods for the separation of HREEs from LREEs in monazite prior to their quantification by ICPOES.

Solution ICP-MS is another powerful and sensitive technique that has been successfully used for the direct determination of several elements in geological materials (7). But the disadvantages of ICP-MS are low tolerance to total dissolved salts, isobaric interferences, and space charge effects. Hence, judicious selection, followed by standardization of sample dissolution/ separation methods to ensure quantitative recovery of all the constituents, while maintaining low TDS levels of sample solutions (below $0.1-0.2 \%$ ), is desirable.

Mineral samples, such as monazite, are refractory and require vigorous conditions, such as elevated temperatures/pressures for dissolution with mineral acids or fusion procedures, to bring about complete decomposition. In the present work, ICP-MS was applied to the determination of all individual REEs as well as the constituents uranium, thorium, and zirconium in monazite samples originating from different places on the coast of India. Two different sample dissolution methods were used: one employing sulphuric acid decomposition and the other using a fusion with a mixture of $\mathrm{KHF}_{2}$ and $\mathrm{NaF}$ (3:1 ratio). A mathematical correction scheme based on oxide yield and abundance data was applied to correct for the mass spectral interferences of LREE oxide ions on HREE ions. Though international monazite reference materials are available, certified or even proposed values are not available for all constituent elements. The certified monazite reference material BGS: IGS-36 (British Geological Survey/Institute of Geological Sciences, U.K.), was analyzed

\section{Atomic Spectroscopy \\ 1 Vol. 34(1), Jan./Feb. 2013}

and the results obtained are presented in this paper.

\section{EXPERIMENTAL}

\section{Instrumentation}

A Platform XS from G.V. Instruments (Micromass) Ltd. (U.K), which is a fully computercontrolled bench top quadrupole ICP-MS, was used for the determination of the elements studied. The instrument is comprised of a hexapole, a four-stage differentially pumped vacuum system with three turbo-pumps, backed by two rotary pumps and a selectable gain conversion dynode-scintillator-photomultiplier detector. The instrumental parameters and operating conditions of the ICP-MS are listed in Table I.

An Ultima-2 ICP-OES from Horiba Jobin Yvon Ltd. (U.K.) was also used for the measurements. The instrumental parameters and operating conditions of the ICP-OES are listed in Table II.

\section{Reagents and Standards}

All solutions were made using grade 1 Millipore ${ }^{\circledR}$ water with a conductivity of $0.4 \mu$ Siemens. Analytical reagent-grade mineral acids were procured and purified further prior to use by sub-boiling distillation. The REE stock solutions were prepared from high purity oxides (99.99\% or $99.999 \%$, Johnson Mathey, U.K) by dissolution in hydrochloric acid. Thorium stock solution $(1 \mathrm{mg} / \mathrm{mL})$ was prepared from thorium nitrate salt (AnalR $\AA$ ) grade). Zirconium stock solution $(1 \mathrm{mg} / \mathrm{mL})$ was prepared using zirconium oxy chloride salt (AnalR ${ }^{\circledR}$ grade). First, single-element $(1000 \mu \mathrm{g} / \mathrm{mL})$ stock solutions were prepared, then working standards containing $100 \mathrm{ng} / \mathrm{mL}, 10 \mathrm{ng} / \mathrm{mL}$, and $1 \mathrm{ng} / \mathrm{mL}$ of each analyte by successive dilutions. Solutions of certified reference materials from Canadian certified reference materials project (CCRMP) SY-2 and SY-3, 
TABLE I

ICP-MS Instrumental Parameters and Operating Conditions

$\begin{array}{ll}\text { Instrument } & \text { Model Platform XS Quadrupole ICP-MS } \\ \text { Cone lens voltage } & -390 \mathrm{~V} \\ \text { Hexapole exit lens voltage } & -380 \mathrm{~V} \\ \text { Hexapole bias } & 0.0 \mathrm{~V} \\ \text { Detector } & \\ \text { Photo multiplier voltage } & 490 \mathrm{~V} \\ \text { Pressures } & \\ \text { Analyzer vacuum } & 10-5 \mathrm{mbar} \\ \text { Torch - forward power } & 1250 \mathrm{~W} \\ \text { Plasma - cool gas } & 13.5 \mathrm{~L} / \mathrm{min} \\ \text { Plasma - intermediate gas } & 1.25 \mathrm{~L} / \mathrm{min} \\ \text { Plasma - nebulizer gas } & 0.8 \mathrm{~L} / \mathrm{min} \\ \text { Hexapole gas - Helium } & 8.0 \mathrm{~mL} / \mathrm{min} \\ \text { Hexapole gas - Hydrogen } & 4.0 \mathrm{~mL} / \mathrm{min} \\ \text { Solution uptake rate (pumped) } & 1 \mathrm{~mL} / \mathrm{min} \\ \text { Spray chamber temperature } & 3-4{ }^{\circ} \mathrm{C} \\ \text { Sampler cone } & \mathrm{Ni}-\mathrm{Cu}, 1.1 \mathrm{~mm} \text { orifice diameter } \\ \text { Skimmer cone } & \mathrm{Ni}, 0.7 \mathrm{~mm} \text { orifice diameter } \\ \text { Acquisition mode } & \text { Peak hopping (SIR) } \\ \text { Dwell time } & 200 \mathrm{~ms}\end{array}$

TABLE II

ICP-OES Instrumental Parameters and Operating Conditions

$\begin{array}{ll}\text { Instrument } & \text { Model Ultima 2 ICP-OES } \\ \text { Mounting } & \text { Czerny-Turner } \\ \text { Focal length } & 1 \mathrm{~m} \\ \text { Grating } & 4320 \text { grooves } / \mathrm{mm} \\ & \& 2400 \text { grooves } / \mathrm{mm} \\ \text { Order of measurement } & 1^{\text {st }} \\ 1^{\text {st }} \text { order resolution } & 0.005 \\ \text { Type of generator } & \text { Solid state } \\ \text { Observation } & \text { Radial View } \\ \text { Frequency of generator } & 40.68 \mathrm{MHz} \\ \text { Power } & 1000 \mathrm{~W} \\ \text { Plasma gas flow rate } & 12 \mathrm{~L} / \mathrm{min} \\ \text { Sheath gas flow rate } & 0.2 \mathrm{~L} / \mathrm{min} \\ \text { Nebulizer gas flow rate } & 0.8 \mathrm{~L} / \mathrm{min} \\ \text { Nebulizer type } & \text { Meinhard }{ }^{\circledR} \\ \text { Type of spray chamber } & \text { Cyclonic } \\ \text { Injector tube diameter } & 1.8 \mathrm{~mm}, \text { Alumina }\end{array}$

were also used for calibration of rare earths, yttrium, uranium, thorium, and zirconium.

\section{Analytical Methodology for Dis- solution of Monazite Samples}

Sulphuric acid decomposition metbod (16)

A 50-mg portion of the sample was accurately weighed into a dry $100-\mathrm{mL}$ beaker, and $10 \mathrm{~mL}$ of $18 \mathrm{~N}$ sulphuric acid was added. The beaker was covered and heated on a sand bath for 2-3 hours (with frequent stirring) until the evolution of dense fumes ended. The beaker was then cooled in an ice bath, and $50 \mathrm{~mL}$ of Millipore ${ }^{\circledR}$ grade water was added to dissolve the residue. The supernatant liquid was then decanted into a 100-mL standard flask. Any insoluble residue remaining was treated with $5 \mathrm{~mL}$ of $18 \mathrm{~N}$ sulphuric acid, and heated on a sand bath until the evolution of dense fumes ended. The residue was cooled, dissolved in $20 \mathrm{~mL}$ of Millipore ${ }^{\circledR}$ grade water and the solution filtered. This filtrate was combined with the first filtrate and made up to $100 \mathrm{~mL}$ using Millipore ${ }^{\circledR}$ grade water. Appropriate aliquots were taken for dilution, maintaining $0.72 \mathrm{~N}$ acidity of sulphuric acid in the final solution. Procedural blank solutions were also prepared concurrently following the same procedure.

\section{Fluoride fusion method (15)}

A 50-mg sample was mixed with $2 \mathrm{~g}$ of flux (a homogenous mixture of $\mathrm{KHF}_{2}$ and $\mathrm{NaF}$ in a 3:1 ratio) in a platinum crucible, covered and fused over a burner until it glowed red for 15 minutes. The crucible was cooled, $10 \mathrm{~mL}$ of $18 \mathrm{~N}$ sulphuric acid was added and heated on a sand bath until the evolution of dense sulphuric acid fumes ended to ensure removal of free fluoride. The contents were cooled, transferred to a beaker with $5 \mathrm{~mL}$ of $12 \mathrm{~N}$ $\mathrm{HCl}$, boiled to get a clear solution, and made up to $100 \mathrm{~mL}$ volume using Millipore ${ }^{\circledR}$ grade water. 
Appropriate aliquots were taken for dilution, maintaining $2 \%(\mathrm{v} / \mathrm{v})$ of $12 \mathrm{~N} \mathrm{HCl}$ in the final solution. Procedural blank solutions were also prepared concurrently following the same procedure.

\section{RESULTS AND DISCUSSION}

\section{Optimization of Instrumental Parameters for Minimizing Oxide Formation}

In the ICP-MS determinations, the oxide levels depend on several instrumental parameters (17). The argon gas flow rate to the nebulizer is the dominant parameter as it has a large effect on both sensitivity and the formation of oxide species. Hence, the nebulizer gas flow rate was optimized for both minimum oxide formation and optimum sensitivity.

\section{Matrix Effects}

In order to minimize polyatomic mass spectral interferences (arising from the medium used for sample dissolution and the sample matrix), the interface effects, the effects due to variations in solution viscosity and the space charge effects arising due to the presence of high quantities of LREEs and thorium, solutions with less than $0.025 \%$ TDS (after appropriate dilution) were analyzed in the present study. Procedural blanks were analyzed concurrently along with the samples and the counts obtained for the blanks were deducted from those of the sample solutions for all isotopes determined.

\section{Selection of Sample Dissolution Methods}

Since monazite is a highly resistant mineral, it is extremely difficult to achieve its complete decomposition/dissolution using combinations of various mineral acids. Since hydrochloric, perchloric, and sulphuric acids pose serious polyatomic ion interference problems in ICPMS, their use is usually avoided.
However, use of one or more of the above reagents becomes a necessity for samples like monazite. Among all mineral acids, sulphuric acid is considered the best reagent to decompose the monazite mineral by using a simple fuming technique on a hot plate for 2-3 hours at $250-300^{\circ} \mathrm{C}$. An acidity of $0.72 \mathrm{~N}$ in the final solution was reported by Murthy et al. (16) as optimum for quantitative recoveries. But doubts about using this fuming method have been expressed by some workers (15) because minor quantities of other heavy refractory minerals (such as zircon, rutile, sillimanite, etc.) occurring along with monazites are not decomposed completely. Hence, fusion with fluxes would be a much more preferable mode of sample dissolution.

Fusion digestion techniques have many advantages over the conventional open acid digestion methods. They do not require the use of hazardous HF or expensive equipment. Further, it is possible to dissolve all common rock-forming minerals, including refractory mineral phases. Different fusion fluxes have been reported for the dissolution of monazite. The use of lithium tetraborate $\left(\mathrm{Li}_{2} \mathrm{~B}_{4} \mathrm{O}_{7}\right)$ has proven to be a very useful way of decomposing the minerals associated with the rare earths, including thorium and uranium (18). Apart from lithium tetraborate, Premdas and Khorge (15) reported fusion with a mixture of potassium bifluoride and sodium fluoride to yield complete decomposition of monazite, including minor quantities of the accessory mineral grains such as zircon, ilmenite, rutile, garnet, sillimanite, etc.

In the present work, both sulphuric acid fuming and fluoride mixture fusion were applied to achieve decomposition of monazite samples, and the results are compared. The use of high purity fusion

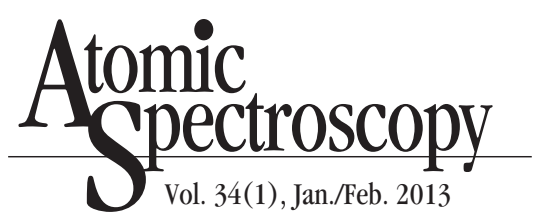

fluxes resulted in extremely low procedural blanks, and the determination limits did not suffer much. The results obtained by both methods agreed well with each other for rare earths, yttrium, uranium, and thorium but a significant difference was observed in the case of zirconium (see discussion later and shown in Tables V, VI, and VII). As indeed observed by other workers (15), in the present work the fluoride fusion method yielded higher recoveries of zirconium compared to the sulphuric acid fuming method for the monazite samples and the certified reference material IGS-36.

\section{Correction of LREE Oxide Ion Interferences on HREE Ions}

Some of the rare earth elements are mono isotopic (Y, Pr, Tb, Ho, and $\mathrm{Tm}$ ), while some others (Nd, $\mathrm{Sm}, \mathrm{Gd}, \mathrm{Dy}$, and $\mathrm{Yb}$ ) have as many as seven isotopes. Hence, in some cases the choice of analyte mass number for ICP-MS analysis is direct, but in others consideration needs to be made both of natural abundances and the degree of oxide formation of potential interfering elements for the selection of the isotope to be used for quantification. Several workers (19-22) have carried out investigations about mass spectroscopic (isobaric) interferences in the determination of REEs by ICP-MS. Apart from the element $\left(\mathrm{M}^{+}\right)$isobaric interferences, oxide $\left(\mathrm{MO}^{+}\right)$as well as hydroxide $\left(\mathrm{MOH}^{+}\right)$isobaric interferences occur in ICP-MS determinations. Generally, the effect from $\mathrm{MOH}^{+}$is considered to be negligible due to very low levels of $\mathrm{MOH}^{+}$formation under standard ICP-MS operating conditions. The most serious interference in the case of rare earths results from mass spectral overlap of the oxide ions $\left(\mathrm{MO}^{+}\right)$of light REEs on middle REEs and heavy REEs as well as matrix-induced $\mathrm{BaO}^{+}, \mathrm{BaOH}^{+}{ }_{n}$ on REEs, i.e., from ${ }^{146} \mathrm{Nd}$ to ${ }^{159} \mathrm{~Tb}$. Since monazite is 
REE-rich, these interferences become much more pronounced compared to routine rock/soil samples. For the chondritic concentration values, the ratio between cerium and lutetium is about $27: 1$, but in the case of monazites this ratio approaches 8000:1. Hence, the problem of light REE oxide interferences on heavy REEs is further aggravated in the case of monazites. Therefore, it is desirable to reduce the oxide levels as much as achievable without decreasing the elemental ion sensitivity too much. Hence, some amount of oxide formation always occurs, even after optimization of several instrumental parameters and correction procedures have been applied.

There are several publications on correction procedures for REE analysis by ICP-MS (19-22). The most prevalent one is based on the measurement of oxide ratios of interfering isotopes using singleelement standard solutions. Singleelement standard solutions of 10 and $100 \mathrm{ppb}$ are used to arrive at the degree of oxide formation of barium and all the REEs under the operating conditions used for the measurements. Then, in combination with natural abundance ratios, correction equations are set up and applied.

This method (22) has been applied in the present study as well. The percentage yields of oxides of all the rare earth isotopes were determined under the operating conditions used for the determinations. The results obtained are given in Table III. Barium showed very low levels of oxidation, and since it occurs at low levels in monazite samples, its interference effect was concluded to be negligible. The degree of formation of oxides for REEs obtained in the present work followed a general pattern obtained by other such studies reported in the literature (17). $\mathrm{La}, \mathrm{Ce}, \mathrm{Pr}$, and $\mathrm{Nd}$ are strong oxide formers. Then, a decrease occurs in oxide formation in the order: $\mathrm{Nd}>\mathrm{Sm}>\mathrm{Eu}$. This was followed by a remarkable increase in the case of $\mathrm{Gd}$, followed by a decrease in the order: $\mathrm{Gd}>\mathrm{Tb}>\mathrm{Dy}>\mathrm{Ho}>\mathrm{Er}>\mathrm{Tm}>\mathrm{Yb}$, and finally an increase of oxide formation again in the case of Lu. Hence, errors on Dy, Ho, Er, and Tm from the lighter REEs (La, Ce, $\mathrm{Pr}, \mathrm{Nd}$ ) are very high due to their higher degree of oxide formation, but the errors due to Sm and Eu are very small as their degree of oxide formation is quite low. Mathematical equations (Table IV) based on the oxide yield data given in Table III and natural abundance data were set up and applied to correct for the above interferences in case of HREE determinations in the present work.

Determination of REEs, Yttrium, Thorium, Uranium, and Zirconium in Monazite Reference Material IGS-36

The Monazite reference material IGS-36 was analyzed using both methods and the results obtained are listed in Table V. The values obtained for the REEs, yttrium, thorium, and uranium by both methods were in good agreement with each other and also with the accepted values reported by Lister (23) thereby validating the results obtained. But a significant difference was observed in the case of zirconium obtained by both methods. The value for zirconium obtained by the fluoride fusion method was much higher than that obtained by the sulphuric acid decomposition method. However, no certified or reference values are available in the literature for zirconium in IGS-36. Hence, the sample solutions obtained by both methods were also analyzed by ICP-OES. The values obtained by ICP-OES agreed with those obtained by ICP-MS, confirming the results. The results obtained indicate quantitative recovery of zirconium by the fusion route over the sulphuric acid fuming route.

\section{Determination of REEs, Yttrium, Thorium, Uranium, and Zirco- nium in Monazite Samples}

Four Indian monazite samples, collected by the Atomic Minerals Directorate for Exploration and Research of India (A.M.D.) from the beach sands of Kerala, Tamil Nadu, and Orissa coast of India, were analyzed by both methods in the present study, and the results obtained are given in Tables VI and VII. The values obtained for REEs, yttrium, uranium, and thorium by both methods were found to be in agreement with each other. The \% RSD for all of the estimated elements varied from 1 to $3 \%$ at the $\mathrm{mg} \mathrm{g}^{-1}$ level and from 5 to $15 \%$ at the $\mu \mathrm{g} \mathrm{g}^{-1}$ levels of concentration. The same sample solutions were also analyzed by ICP-OES. The results obtained (Tables VI and VII) compared well with those obtained by ICP-OES. However, in the case of zirconium, the fluoride fusion route gave higher values indicating quantitative recovery, which was confirmed since the results agreed with those obtained by ICP-OES.

\section{CONCLUSION}

The results obtained in the present work show that monazite samples should be digested using fluoride fusion when quantification of refractory elements like zirconium is required. However, both the sulphuric acid fuming and the fluoride fusion methods yield good results for the ICP-MS determination of rare earth elements, yttrium, uranium, and thorium. The validity of the methods applied in the present work was verified by analyzing the IGS-36 standard reference monazite sample. This study illustrates the importance of careful selection of the dissolution step when analyzing geological materials, especially refractory minerals by ICP-MS. The proposed methods involve a simple 


\section{Atomic Mpectroscopy \\ $\bigcup$ Vol. 34(1), Jan./Feb. 2013}

TABLE III

Formation Yield of Mono-oxide Ions of REEs, Ba, and Their Interferences

\begin{tabular}{|c|c|c|c|c|}
\hline $\begin{array}{l}\text { Interfering REEs } \\
\text { Nuclide }\left(\mathrm{M}^{+}\right)\end{array}$ & \% Abundance & $\begin{array}{c}\text { Corresponding } \\
\text { Mono-Oxide }\left(\mathrm{MO}^{+}\right)\end{array}$ & $\begin{array}{l}\text { Formation Yield of Oxide } \\
\left(\mathrm{MO}^{+} / \mathrm{M}^{+}\right) \%\end{array}$ & $\begin{array}{c}\text { Interfered REEs } \\
\text { Nuclide }\left(\mathrm{M}^{+}\right)\end{array}$ \\
\hline${ }^{135} \mathrm{Ba}$ & 6.6 & ${ }^{135} \mathrm{BaO}$ & 0.1 & ${ }^{151} \mathrm{Eu}$ \\
\hline${ }^{136} \mathrm{Ba}$ & 7.8 & ${ }^{136} \mathrm{BaO}$ & 0.2 & ${ }^{152} \mathrm{Sm}$ \\
\hline${ }^{137} \mathrm{Ba}$ & 11.3 & ${ }^{137} \mathrm{BaO}$ & 0.2 & ${ }^{153} \mathrm{Eu}$ \\
\hline${ }^{138} \mathrm{Ba}$ & 71.7 & ${ }^{138} \mathrm{BaO}$ & 0.1 & ${ }^{154} \mathrm{Sm}$ \\
\hline${ }^{139} \mathrm{La}$ & 99.9 & ${ }^{139} \mathrm{LaO}$ & 1.4 & ${ }^{155} \mathrm{Gd}$ \\
\hline${ }^{140} \mathrm{Ce}$ & 88.5 & ${ }^{140} \mathrm{CeO}$ & 1.5 & ${ }^{156} \mathrm{Gd}$ \\
\hline${ }^{142} \mathrm{Ce}$ & 11.1 & ${ }^{142} \mathrm{CeO}$ & 1.4 & ${ }^{158} \mathrm{Gd}$ \\
\hline${ }^{141} \mathrm{Pr}$ & 100 & ${ }^{141} \mathrm{PrO}$ & 0.5 & ${ }^{157} \mathrm{Gd}$ \\
\hline${ }^{143} \mathrm{Nd}$ & 12.1 & ${ }^{143} \mathrm{NdO}$ & 0.5 & ${ }^{159} \mathrm{~Tb}$ \\
\hline${ }^{144} \mathrm{Nd}$ & 23.8 & ${ }^{144} \mathrm{NdO}$ & 0.5 & ${ }^{160} \mathrm{Gd}$ \\
\hline${ }^{146} \mathrm{Nd}$ & 17.2 & ${ }^{146} \mathrm{NdO}$ & 0.4 & ${ }^{162} \mathrm{Dy}$ \\
\hline${ }^{147} \mathrm{Sm}$ & 15.1 & ${ }^{147} \mathrm{SmO}$ & 0.3 & ${ }^{163} \mathrm{Dy}$ \\
\hline${ }^{149} \mathrm{Sm}$ & 13.8 & ${ }^{149} \mathrm{SmO}$ & 0.3 & ${ }^{165} \mathrm{Ho}$ \\
\hline${ }^{151} \mathrm{Eu}$ & 47.8 & ${ }^{151} \mathrm{EuO}$ & $<0.1$ & ${ }^{167} \mathrm{Er}$ \\
\hline${ }^{153} \mathrm{Eu}$ & 52.2 & ${ }^{153} \mathrm{EuO}$ & $<0.1$ & ${ }^{169} \mathrm{Tm}$ \\
\hline${ }^{155} \mathrm{Gd}$ & 14.7 & ${ }^{155} \mathrm{GdO}$ & 1.5 & ${ }^{171} \mathrm{Yb}$ \\
\hline${ }^{156} \mathrm{Gd}$ & 20.5 & ${ }^{156} \mathrm{GdO}$ & 1.8 & ${ }^{172} \mathrm{Yb}$ \\
\hline${ }^{157} \mathrm{Gd}$ & 15.7 & ${ }^{157} \mathrm{GdO}$ & 1.8 & ${ }^{173} \mathrm{Yb}$ \\
\hline${ }^{158} \mathrm{Gd}$ & 24.9 & ${ }^{158} \mathrm{GdO}$ & 1.5 & ${ }^{174} \mathrm{Yb}$ \\
\hline${ }^{160} \mathrm{Gd}$ & 21.9 & ${ }^{160} \mathrm{GdO}$ & 1.2 & ${ }^{176} \mathrm{Yb}$ \\
\hline${ }^{159} \mathrm{~Tb}$ & 100 & ${ }^{159} \mathrm{TbO}$ & 1.0 & ${ }^{175} \mathrm{Lu}$ \\
\hline${ }^{161} \mathrm{Dy}$ & 18.9 & ${ }^{161} \mathrm{DyO}$ & 0.2 & - \\
\hline${ }^{163} \mathrm{Dy}$ & 25.0 & ${ }^{163} \mathrm{DyO}$ & 0.2 & - \\
\hline${ }^{164} \mathrm{Dy}$ & 18.9 & ${ }^{164} \mathrm{DyO}$ & 0.2 & - \\
\hline${ }^{165} \mathrm{Ho}$ & 100 & ${ }^{165} \mathrm{HoO}$ & 0.1 & - \\
\hline${ }^{166} \mathrm{Er}$ & 33.4 & ${ }^{166} \mathrm{ErO}$ & 0.1 & - \\
\hline${ }^{168} \mathrm{Er}$ & 27.1 & ${ }^{168} \mathrm{ErO}$ & 0.1 & - \\
\hline${ }^{169} \mathrm{Tm}$ & 100 & ${ }^{169} \mathrm{TmO}$ & $<0.1$ & - \\
\hline${ }^{171} \mathrm{Yb}$ & 14.3 & ${ }^{171} \mathrm{YbO}$ & $<0.1$ & - \\
\hline${ }^{172} \mathrm{Yb}$ & 21.8 & ${ }^{172} \mathrm{YbO}$ & $<0.1$ & - \\
\hline${ }^{175} \mathrm{Lu}$ & 97.4 & ${ }^{175} \mathrm{LuO}$ & 0.4 & - \\
\hline
\end{tabular}

methodology as mathematical correction equations have been effectively used for mass spectral interference correction. No additional analytical steps needed to be employed for the separation of rare earths, uranium, thorium, etc., to minimize such interferences.

\section{ACKNOWLEDGMENT}

The authors thank Mr. P.S. Parihar, Director, and Dr. P.V. Ramesh Babu, Addl. Director (R\&D), A.M.D., for their encouragement and support in carrying out this work. The authors also thank Dr. K. Shivkumar, Head, MPG Group, A.M.D., for his valuable suggestions and the Petrology and XRD laboratories of A.M.D., Hyderabad, for providing the samples.
Received August 28, 2012 
TABLE IV

Equations for Correction of LREE Oxide Ion Interferences on HREE Ions

\begin{tabular}{|c|c|c|}
\hline Interfered Ion & Interfering Oxide Ion & Correction Equation \\
\hline \multirow[t]{2}{*}{${ }^{160} \mathrm{Gd}$} & ${ }^{144} \mathrm{Nd}^{16} \mathrm{O}$ & $\mathrm{C}_{\text {Gd,sample }}^{\mathrm{a}}=\left\{\mathrm{I}_{160 \mathrm{Gd}, \text { sample }}^{\mathrm{b}}-\mathrm{I}^{\mathrm{b}}{ }_{144 \mathrm{Nd}, \text { sample }}\left(\mathrm{F} . \mathrm{Y}^{\mathrm{c}}{ }_{144 \mathrm{NdO} / 144 \mathrm{Nd}}\right)\right\} \mathrm{C}_{\mathrm{Gd}, \text { standard }}^{\mathrm{a}}$ \\
\hline & & $\mathrm{I}^{\mathrm{b}}{ }_{160 \mathrm{Gd}, \text { standard }}$ \\
\hline \multirow[t]{2}{*}{${ }^{159} \mathrm{~Tb}$} & ${ }^{143} \mathrm{Nd}^{16} \mathrm{O}$ & $\mathrm{C}_{\mathrm{Tb}, \text { sample }}^{\mathrm{a}}=\left\{\mathrm{I}^{\mathrm{b}}{ }_{157 \mathrm{~Tb}, \text { sample }}-\mathrm{I}^{\mathrm{b}}{ }_{143 \mathrm{Nd}, \text { sample }}\left(\mathrm{F} . \mathrm{Y}^{\mathrm{c}}{ }_{143 \mathrm{NdO} / 143 \mathrm{Nd}}\right)\right\} \mathrm{C}^{\mathrm{a}}{ }_{\mathrm{Tb}, \text { standard }}$ \\
\hline & & $\mathrm{I}^{\mathrm{b}}{ }_{159 \mathrm{~Tb}, \text { standard }}$ \\
\hline \multirow[t]{2}{*}{${ }^{164} \mathrm{Dy}$} & ${ }^{148} \mathrm{Nd}^{16} \mathrm{O}$ & $\mathrm{C}_{\text {Dy,sample }}^{\mathrm{a}}=\left\{\mathrm{I}^{\mathrm{b}}{ }_{164 \mathrm{Dy}, \text { sample }}-\mathrm{I}^{\mathrm{b}}{ }_{148 \mathrm{Nd}, \text { sample }}\left(\mathrm{F} . \mathrm{Y}^{\mathrm{c}}{ }_{148 \mathrm{NdO} / 148 \mathrm{Nd})}\right\} \mathrm{C}^{\mathrm{a}}\right.$ Dy,standard \\
\hline & & $\mathrm{I}^{\mathrm{b}}{ }_{164 \mathrm{Dy}, \text { standard }}$ \\
\hline \multirow[t]{2}{*}{${ }^{165} \mathrm{Ho}$} & ${ }^{149} \mathrm{Sm}^{16} \mathrm{O}$ & $\mathrm{C}_{\text {Ho,sample }}^{\mathrm{a}}=\left\{\mathrm{I}^{\mathrm{b}}{ }_{165 \mathrm{Ho}, \text { sample }}-\mathrm{I}^{\mathrm{b}}{ }_{149 \mathrm{Sm}, \text { sample }}\left(\mathrm{F} . \mathrm{Y}^{\mathrm{c}}{ }_{149 \mathrm{SmO} / 149 \mathrm{Sm}}\right)\right\} \mathrm{C}^{\mathrm{a}}{ }_{\text {Ho,standard }}$ \\
\hline & & $\mathrm{I}^{\mathrm{b}}{ }_{165 \mathrm{Ho}, \text { standard }}$ \\
\hline \multirow[t]{2}{*}{${ }^{171} \mathrm{Yb}$} & ${ }^{155} \mathrm{Gd}^{16} \mathrm{O}$ & $\mathrm{C}_{\text {Yb,sample }}^{\mathrm{a}}=\left\{\mathrm{I}^{\mathrm{b}}{ }_{171 \mathrm{Yb}, \text { sample }}-\mathrm{I}^{\mathrm{b}}{ }_{155 \mathrm{Gd} \text {,sample }}\left(\mathrm{F} . \mathrm{Y}^{\mathrm{c}}{ }_{155 \mathrm{GdO} / 155 \mathrm{Gd}}\right)\right\} \mathrm{C}^{\mathrm{a}}$ Yb,standard \\
\hline & & $\mathrm{I}^{\mathrm{b}} 171 \mathrm{Yb}$, standard \\
\hline \multirow[t]{2}{*}{${ }^{175} \mathrm{Lu}$} & ${ }^{159} \mathrm{~Tb}^{16} \mathrm{O}$ & $\mathrm{C}_{\text {Lu,sample }}^{\mathrm{a}}=\left\{\mathrm{I}^{\mathrm{b}}{ }_{175 \mathrm{Lu}, \text { sample }}-\mathrm{I}^{\mathrm{b}}{ }_{159 \mathrm{~Tb}, \text { sample }}\left(\mathrm{F} . \mathrm{Y}^{\mathrm{c}}{ }^{\mathrm{c}}{ }_{159 \mathrm{TbO} / 159 \mathrm{~Tb}}\right)\right\} \mathrm{C}_{\text {Lu, standard }}^{\mathrm{a}}$ \\
\hline & & $\mathrm{I}^{\mathrm{b}}{ }_{175 \mathrm{Lu}, \text { standard }}$ \\
\hline
\end{tabular}

${ }^{\mathrm{a}}$ Concentration. $\quad{ }^{\mathrm{b}}$ Ion count at the specific mass number. $\quad{ }^{\mathrm{c}}$ F.Y.: Formation Yield of Oxide.

TABLE V

Analytical Results of Rare Earths, Yttrium, Thorium, Uranium, and Zirconium in Monazite Reference Material IGS-36

\begin{tabular}{|c|c|c|c|c|c|c|c|}
\hline \multirow{2}{*}{\multicolumn{2}{|c|}{ Analyte/Mass No. }} & \multirow{2}{*}{\multicolumn{2}{|c|}{$\begin{array}{l}\text { Value obtained }^{\text {a }} \\
\text { by ICP-MS after } \\
\text { sulphuric acid } \\
\text { decomposition method }\end{array}$}} & \multirow{2}{*}{\multicolumn{2}{|c|}{$\begin{array}{l}\text { Value Obtained } \\
\text { by ICP-MS after } \\
\mathrm{KHF}_{2}-\mathrm{NaF} \\
\text { fusion method }\end{array}$}} & \multicolumn{2}{|c|}{ Reported Value (23) } \\
\hline & & & & & & \multicolumn{2}{|c|}{$\begin{array}{cc}\begin{array}{c}\text { Probable } \\
\text { value }\end{array} & \begin{array}{c}\text { Range } \\
\text { (95\% confidence } \\
\text { limits })\end{array}\end{array}$} \\
\hline $\mathrm{Y}$ & $89(\%)$ & 0.86 & $(1.0)$ & 0.94 & $(1.6)$ & 0.88 & $0.83-0.94$ \\
\hline $\mathrm{La}$ & $139(\%)$ & 9.64 & $(2.6)$ & 9.90 & (1.8) & 10.17 & $9.51-10.51$ \\
\hline $\mathrm{Ce}$ & $140(\%)$ & 20.0 & $(3.0)$ & 20.5 & $(3.2)$ & 20.28 & $19.9-20.5$ \\
\hline $\operatorname{Pr}$ & $141(\%)$ & 2.08 & $(3.4)$ & 2.18 & $(2.0)$ & 2.31 & $2.22-2.38$ \\
\hline $\mathrm{Nd}$ & $146(\%)$ & 8.84 & $(2.8)$ & 9.16 & (1.8) & 9.00 & $8.75-9.41$ \\
\hline Sm & $147(\%)$ & 1.33 & $(2.5)$ & 1.38 & $(3.2)$ & 1.33 & $1.24-1.41$ \\
\hline $\mathrm{Eu}$ & $151\left(\mu \mathrm{g} \mathrm{g}^{-1}\right)$ & 280 & $(6.9)$ & 286 & $(7.1)$ & 301 & $282-320$ \\
\hline Gd & $160(\%)$ & 0.65 & $(5.1)$ & 0.69 & $(4.0)$ & 0.67 & $0.64-0.70$ \\
\hline $\mathrm{Tb}$ & $159\left(\mu \mathrm{g} \mathrm{g}^{-1}\right)$ & 780 & $(4.1)$ & 740 & $(5.0)$ & 935 & $680-1190$ \\
\hline Dy & $164(\%)$ & 0.30 & $(3.0)$ & 0.29 & $(2.4)$ & 0.27 & $0.24-0.30$ \\
\hline Ho & $165\left(\mu \mathrm{g} \mathrm{g}^{-1}\right)$ & 372 & $(5.7)$ & 356 & $(6.0)$ & 347 & - \\
\hline Er & $167\left(\mu \mathrm{g} \mathrm{g}^{-1}\right)$ & 520 & $(5.8)$ & 564 & $(6.0)$ & 535 & - \\
\hline $\mathrm{Tm}$ & $169\left(\mu \mathrm{g} \mathrm{g}^{-1}\right)$ & 50 & (13.0) & 50 & (14.1) & 57 & - \\
\hline $\mathrm{Yb}$ & $171\left(\mu \mathrm{g} \mathrm{g}^{-1}\right)$ & 280 & (10.9) & 280 & (11.3) & 259 & $234-284$ \\
\hline $\mathrm{Lu}$ & $175\left(\mu \mathrm{g} \mathrm{g}^{-1}\right)$ & 50 & $(15.7)$ & 58 & $(15.2)$ & 51 & - \\
\hline $\mathrm{Th}$ & $232(\%)$ & 5.44 & $(5.4)$ & 5.54 & $(4.5)$ & $5.38^{\mathrm{b}}$ & 5.24-5.52 \\
\hline $\mathrm{U}$ & $238(\%)$ & 0.23 & $(7.1)$ & 0.25 & $(8.0)$ & 0.20 & $0.17-0.23$ \\
\hline $\mathrm{Zr}$ & $90(\%)$ & 0.01 & (8.3) & 3.5 & (3.9) & n.a $\left(3.45^{\mathrm{c}}\right)$ & ) - \\
\hline
\end{tabular}

${ }^{a}$ All values are a mean of $n=4$ replicates with $\%$ relative standard deviation shown in parentheses.

${ }^{\mathrm{b}}$ Recommended value. $\quad$ c ICP-OES value. n.a $=$ not available. 


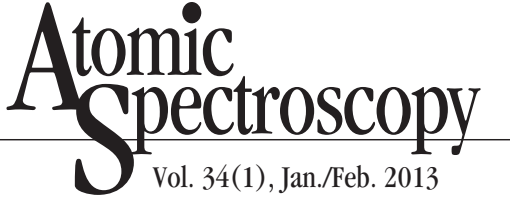

TABLE VI

Analytical Results of Rare Earths, Yttrium, Thorium, Uranium, and Zirconium in Indian Monazite Samples

\begin{tabular}{|c|c|c|c|c|c|c|c|c|}
\hline \multirow{3}{*}{ Analyte/Mass No. } & \multicolumn{4}{|c|}{ Sample No. AMD-450 } & \multicolumn{4}{|c|}{ Sample No. AMD-1155 } \\
\hline & \multicolumn{2}{|c|}{$\begin{array}{l}\text { Value obtained after } \\
\text { sulphuric acid } \\
\text { decomposition }\end{array}$} & \multicolumn{2}{|c|}{$\begin{array}{l}\text { Value obtained after } \\
\mathrm{KHF}_{2}-\mathrm{NaF} \text { fusion }\end{array}$} & \multicolumn{2}{|c|}{$\begin{array}{c}\text { Value obtained after } \\
\text { sulphuric acid } \\
\text { decomposition }\end{array}$} & \multicolumn{2}{|c|}{$\begin{array}{l}\text { Value obtained after } \\
\mathrm{KHF}_{2}-\mathrm{NaF} \text { fusion }\end{array}$} \\
\hline & By ICP-MS $^{\mathrm{a}}$ B & By ICP-OES & By ICP-MS ${ }^{\mathrm{a}}$ B & CP-OES & By ICP-MS ${ }^{a}$ B & ICP-OES & By ICP-MS $^{\mathrm{a}}$ B & By ICP-OES \\
\hline Y $89(\%)$ & $1.51 \quad(1.8)$ & 1.6 & $1.814(2.1)$ & 1.76 & $0.30 \quad(2.3)$ & 0.31 & $0.31 \quad(2.8)$ & 0.28 \\
\hline La $139(\%)$ & $7.84 \quad(2.2)$ & 7.6 & $8.06 \quad(2.9)$ & 8.4 & $12.98(2.3)$ & 13.92 & $13.26(1.8)$ & 13.6 \\
\hline Ce $140(\%)$ & $19.76(3.1)$ & 19.72 & $18.96(3.2)$ & 19.6 & $23.2(2.4)$ & 23.28 & $23.0 \quad(2.1)$ & 23.7 \\
\hline $\operatorname{Pr} 141(\%)$ & $1.996(2.0)$ & 1.86 & $2.046(1.6)$ & 2.00 & 2.38 (2.2) & 2.42 & $2.44 \quad(2.4)$ & 2.36 \\
\hline Nd $146(\%)$ & $7.92 \quad(2.6)$ & 7.32 & $8.08 \quad(2.7)$ & 8.52 & $8.60 \quad(2.4)$ & 8.70 & $(3.3)$ & 8.9 \\
\hline Sm $147(\%)$ & $2.46 \quad(3.7)$ & 2.4 & $2.42 \quad(4.0)$ & 2.6 & $1.32(4.4)$ & 1.20 & $1.36 \quad(4.7)$ & 1.2 \\
\hline Eu151 $\left(\mu \mathrm{g} \mathrm{g}^{-1}\right)$ & $(10.0)$ & 130 & $(10.8)$ & 120 & $194 \quad(10.0)$ & 180 & (11.1) & 190 \\
\hline Gd $160(\%)$ & $1.37 \quad(4.8)$ & 1.21 & $1.42 \quad(4.0)$ & 1.25 & $0.51 \quad(2.8)$ & 0.49 & $0.51 \quad(2.6)$ & 0.44 \\
\hline Tb $159\left(\mu \mathrm{g} \mathrm{g}^{-1}\right)$ & 1120 (9.4) & 960 & $1120(8.0)$ & 1000 & $620 \quad(2.3)$ & 600 & $(2.5)$ & 552 \\
\hline Dy $164(\%)$ & $0.49 \quad(3.4)$ & 0.56 & $0.48 \quad(4.3)$ & 0.51 & $0.12 \quad(3.6)$ & 0.14 & $0.14 \quad(2.9)$ & 0.15 \\
\hline Ho $165\left(\mu \mathrm{g} \mathrm{g}^{-1}\right)$ & (11.9) & 440 & (11.4) & 488 & $110 \quad(12.5)$ & 120 & (13.1) & 130 \\
\hline $\operatorname{Er} 167\left(\mu g^{-1}\right)$ & (6.8) & 765 & $(5.7)$ & 780 & $135 \quad(8.5)$ & 148 & $(9.3)$ & 292 \\
\hline $\operatorname{Tm} 169\left(\mu \mathrm{g} \mathrm{g}^{-1}\right)$ & (12.9) & $<100$ & (12.2) & $<100$ & (14.8) & $<100$ & (15.0) & $<100$ \\
\hline Yb $171\left(\mu \mathrm{g} \mathrm{g}^{-1}\right)$ & $(8.3)$ & 350 & $(7.4)$ & 360 & $120 \quad(12.5)$ & 150 & (11.8) & 160 \\
\hline Lu $175\left(\mu \mathrm{g} \mathrm{g}^{-1}\right)$ & (14.9) & $<100$ & (13.8) & $<100$ & $(13.4)$ & $<100$ & (12.9) & $<100$ \\
\hline Th 232 (\%) & $10.8 \quad(3.4)$ & 10.3 & $11.5 \quad(3.8)$ & 11.0 & $6.82(4.0)$ & 6.56 & $7.18 \quad(3.8)$ & 6.88 \\
\hline U $238(\%)$ & $0.29 \quad(5.5)$ & 0.28 & $0.32 \quad(5.3)$ & 0.34 & $0.19 \quad(6.8)$ & 0.17 & $0.21 \quad(6.5)$ & 0.18 \\
\hline $\mathrm{Zr} 90\left(\mu \mathrm{g} \mathrm{g}^{-1}\right)$ & (11.0) & $<100$ & $(10.5)$ & 108 & (15.3) & $<100$ & (2.8) & 440 \\
\hline
\end{tabular}

${ }^{a}$ All values are a mean of $n=4$ replicates with $\%$ relative standard deviation shown in parentheses.

\section{REFERENCES}

1. A.R. Date and D. Hutchison, J. Anal. At. Spectrom. 2, 269 (1987)

2. R.K. Malhotra, Proceedings of 10th ISAS National Symposium on Strategic and Hi-Tech Metals, Udaipur, India, IL-15, p. 1 (1994).

3. R.R. Parrish, Canadian J. of Earth Sciences 27, 1431 (1990).

4. I. Roelandt, Chem. Geol. 67, 171 (1986).

5. R. Parthasarathy, H.B. Desai and S.R. Kayasth, J. Radioanal. Nucl. Chem. Lett. 105(5), 277 (1986).

6. J.N. Walsh, F. Buckley and J. Barker, Chem. Geol. 33, 141 (1981).

7. M. Thompson and J.N. Walsh, A Handbook of Inductively Coupled Plasma Spectrometry (ed. Blackie), Glasgow, London, U.K. (1983).
8. J.G. Crock and F.E. Lichte, Anal. Chem. 54, 1329 (1982).

9. J.G. Crock, F.E. Lichte and T.R. Wildeman, Chem. Geol. 45, 149 (1984).

10. R.M. Cassidy, Chem. Geol. 67, 185 (1988).

11. I. Kwasaki, K. Fuwa and H. Haraguchi, Anal. Chim. Acta 183, 239 (1986).

12. R. Jeya, P.K. Thampi, and G. Balasubramanian, Anal. Lett. 39, 2297 (2006).

13. R. Jeya, G. Balasubramanian and P.K. Thampi, Current Science 94(10), 1296 (2008).

14. E.H. Borai, M.A. Eid and H.F. Aly, Anal. Bioanal. Chem. 372, 537 (2002).

15. A. Premdas and C.R. Khorge, At. Spectrosc. 27(5), 170 (2006)
16. D.S.R. Murty, B.K. Balaji and S.P. Balakrishnan, At. Spectrosc. 11(4), 112 (1990).

17. H.P. Longerich, B.J. Fryer, D.F. Strong and C.K. Kantipuly, Spectrochim. Acta Part B 42(1/2), 75 (1987).

18. P. Roy, V. Balaram, A. Bhattacharaya, P. Nasipuri and M. Satyanarayanan, Current Science 93(8), 1122 (2007).

19. J.R. Baxcon and A.M. Ure, Anal. Chim. Acta 105,163 (1979).

20. W. Doherty and A. Vander Voet, Can. J. Spectrosc. 30,135 (1985).

21. M.A. Vaughan and G. Horlick, Appl. Spectrosc. 44, 587 (1990).

22. X. Cao, M. Yin and X. Wang, Spectrochim. Acta Part B 56, 431 (2001).

23. B. Lister, Geostd. Newsl. 5, 75 (1981). 
TABLE VII

Analytical Results of Rare Earths, Yttrium, Thorium, Uranium, and Zirconium in Indian Monazite Samples

\begin{tabular}{|c|c|c|c|c|c|c|c|c|}
\hline \multirow{3}{*}{ Analyte/Mass No. } & \multicolumn{4}{|c|}{ Sample No. AMD-5485 } & \multicolumn{4}{|c|}{ Sample No. AMD-6796 } \\
\hline & \multicolumn{2}{|c|}{$\begin{array}{l}\text { Value obtained after } \\
\text { sulphuric acid } \\
\text { decomposition }\end{array}$} & \multicolumn{2}{|c|}{$\begin{array}{l}\text { Value obtained after } \\
\mathrm{KHF}_{2-} \text { NaF fusion }\end{array}$} & \multicolumn{2}{|c|}{$\begin{array}{c}\text { Value obtained after } \\
\text { sulphuric acid } \\
\text { decomposition }\end{array}$} & \multicolumn{2}{|c|}{$\begin{array}{l}\text { Value obtained after } \\
\mathrm{KHF}_{2-} \text { NaF fusion }\end{array}$} \\
\hline & By ICP-MS ${ }^{\mathrm{a}}$ & By ICP-OES & By ICP-MS $^{\mathrm{a}} \quad \mathrm{B}$ & By ICP-OES & By ICP-MS ${ }^{\mathrm{a}}$ & By ICP-OES & By ICP-MS $^{\mathrm{a}}$ & By ICP-OES \\
\hline Y $89(\%)$ & $0.28 \quad(4.5)$ & 0.29 & $(5.0)$ & 0.296 & 2.69 (1.9) & 2.90 & 2.88 (1.0) & 2.92 \\
\hline La $139(\%)$ & $11.72(2.9)$ & 12.4 & $12.84(2.4)$ & 12.4 & $10.4 \quad(3.4)$ & 11.12 & $10.92(2.5)$ & 11.32 \\
\hline Ce $140(\%)$ & $25.4 \quad(1.6)$ & 25.2 & $27.52(2.2)$ & 25.2 & $21.0 \quad(2.1)$ & 22.12 & $21.7 \quad(2.8)$ & 22.56 \\
\hline $\operatorname{Pr} 141(\%)$ & $2.21 \quad$ (3.8) & 2.4 & $(3.1)$ & 2.28 & $(2.6)$ & 1.82 & $1.84 \quad(2.4)$ & 1.804 \\
\hline Nd $146(\%)$ & $9.32 \quad(2.5)$ & 8.5 & $10.16(2.4)$ & 9.68 & $(2.9)$ & 6.96 & 6.88 (2.6) & 7.04 \\
\hline Sm $147(\%)$ & $1.14 \quad(3.4)$ & 1.14 & $(3.7)$ & 1.18 & $0.96(4.3)$ & 1.06 & $1.08 \quad(3.4)$ & 1.03 \\
\hline $\operatorname{Eu} 151\left(\mu \mathrm{g} \mathrm{g}^{-1}\right)$ & $(10.7)$ & 132 & (12.1) & 132 & 276 & 298 & $(8.9)$ & 292 \\
\hline Gd $160(\%)$ & $0.64 \quad(4.6)$ & 0.6 & $(5.0)$ & 0.56 & $0.67 \quad(5.4)$ & 0.69 & $0.71 \quad(6.1)$ & 0.67 \\
\hline Tb $159\left(\mu \mathrm{g} \mathrm{g}^{-1}\right)$ & $(7.3)$ & 550 & $(7.4)$ & 588 & $784 \quad(6.3)$ & 793 & $(7.0)$ & 776 \\
\hline Dy $164(\%)$ & $0.14 \quad(6.6)$ & 0.16 & $(7.7)$ & 0.14 & $0.50 \quad(3.9)$ & 0.54 & $0.53 \quad(3.8)$ & 0.54 \\
\hline Ho $165\left(\mu \mathrm{g} \mathrm{g}^{-1}\right)$ & $(14.7)$ & 200 & (13.5) & 148 & $\begin{array}{ll}752 & (8.5)\end{array}$ & 836 & $825 \quad(8.9)$ & 848 \\
\hline $\operatorname{Er} 167\left(\mu \mathrm{g} \mathrm{g}^{-1}\right)$ & $(9.0)$ & 300 & $(7.9)$ & 320 & $1860(5.2)$ & 2000 & $1920(6.1)$ & 2092 \\
\hline $\operatorname{Tm} 169\left(\mu \mathrm{g} \mathrm{g}^{-1}\right)$ & (14.7) & $<100$ & (13.3) & $<100$ & 148 (10.6) & 172 & (11.1) & 220 \\
\hline $\mathrm{Yb} 171\left(\mu \mathrm{g} \mathrm{g}^{-1}\right)$ & (12.8) & 170 & (11.6) & 180 & $1520(5.6)$ & 1620 & $1600(6.7)$ & 1640 \\
\hline Lu $175\left(\mu \mathrm{g} \mathrm{g}^{-1}\right)$ & (12.8) & $<100$ & $(15.7)$ & $<100$ & $196 \quad(12.2)$ & 224 & $208 \quad(13.1)$ & 240 \\
\hline Th 232 (\%) & $(2.6)$ & 8.1 & $(2.7)$ & 7.96 & 6.85 (4.9) & 6.3 & $7.04 \quad(5.1)$ & 7.32 \\
\hline U $238(\%)$ & $0.29 \quad(8.4)$ & 0.32 & $(7.9)$ & 0.36 & 0.23 (6.3) & 0.25 & $(5.9)$ & 0.308 \\
\hline $\mathrm{Zr} 90\left(\mu \mathrm{g} \mathrm{g}^{-1}\right)$ & (15.1) & $<100$ & 1520 & 1492 & $(10.2)$ & $<100$ & $4360(5.0)$ & 3840 \\
\hline
\end{tabular}

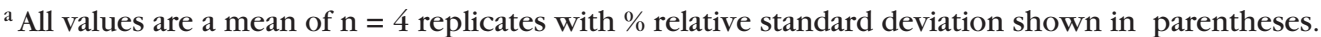

